\title{
EVALUATION OF ANTIDEPRESSANT ACTIVITY OF ETHANOLIC EXTRACT OF LAGERSTROEMIA SPECIOSA LEAVES IN ALBINO WISTAR RATS
}

\author{
VANITA KANASE, SUNITA VISHWAKARMA* \\ Department of Pharmacology, Oriental College of Pharmacy, Navi Mumbai, Maharashtra, India. Email: sunitapharmacy1@gmail.com
}

Received: 22 September 2019, Revised and Accepted: 12 December 2019

ABSTRACT

Objective: The objective of the study was to evaluate the antidepressant activity of ethanolic extract of dried leaves of Lagerstroemia speciosa L. (EELS) on acute restraint stress (ARS)-induced depression-like behavior and biochemical alterations in albino wistar rats.

\begin{abstract}
Methods: Thirty rats were randomly divided into five experimental groups. Group-I (normal control) rats received normal saline (2.0 ml $/ \mathrm{kg}$, p.o.) daily for 14 days; Group-II (stress control) rats received normal saline $(2.0 \mathrm{ml} / \mathrm{kg}$, p.o.) daily for 14 days and subjected to restraint stress on the $13^{\text {th }}$ day. Group-III (standard drug-treated) rats received imipramine $\left(15 \mathrm{mg} / \mathrm{kg}\right.$, p.o.) daily for 14 days and subjected to restraint stress on the $13^{\text {th }}$ day. Groups-IV and V rats were treated with EELS $\left(100 \mathrm{mg} / \mathrm{kg}\right.$ and $300 \mathrm{mg} / \mathrm{kg}$, p.o.) daily for 14 days subjected to ARS on the $13^{\text {th }}$ day. Stress-like behavior was assessed by subjecting the rats to behavioral paradigms such as tail-suspension test (TST) and open field test (OFT), 40 min post-restraint stress procedure. Pretest of $10 \mathrm{~min}$ for forced swim test (FST) was also given to each rat simultaneously. Then, $23.5 \mathrm{~h}$ later, the relevant samples were administered and the main test performed 30 min later. Oxidative stress parameters such as superoxide dismutase (SOD), catalase (CAT), malondialdehyde (MDA), and extent of lipid peroxidation (LPO) were analyzed in restraint stress-induced animals and control group, following FST on the $15^{\text {th }}$ day.
\end{abstract}

Statistical Analysis: Expression of data was done as a mean standard error of the mean. The normally distributed data were subjected to one-way analysis of variance followed by Dunnett's test. ${ }^{*} \mathrm{p}<0.05$ was considered statistically significant.

Results: It was observed that L. speciosa L. showed a significant dose-dependent decrease in duration of immobility time in TST and FST when compared with the control group in a dose-dependent manner. The results of OFT also showed a dose-dependent increase in locomotor activity. In addition to behavioral tests, EELS also normalized oxidative stress markers such as CAT, SOD, MDA, and LPO in a dose-dependent manner.

Conclusion: The results suggest that the ethanolic extract of $L$. speciosa L. leaves possesses significant antidepressant property, may be recommended as a supplement for the antidepressant activity.

Keywords: Lagerstroemia speciosa, Antidepressant, Acute restraint stress, Tail-suspension test, Open filed test, Forced swimming test, Imipramine, Biochemical estimation.

(c) 2020 The Authors. Published by Innovare Academic Sciences Pvt Ltd. This is an open access article under the CC BY license (http://creativecommons. org/licenses/by/4. 0/) DOI: http://dx.doi.org/10.22159/ajpcr.2020.v13i2.35823

\section{INTRODUCTION}

Depression is a heterogeneous disorder that affects a person's mood, physical health, and behavior. It is caused not only by changing lifestyle as perceived by the general public but also by some of the allopathic drugs, for example, an anti-hypertensive drug, reserpine that depletes neuronal storage granules of norepinephrine (NE), serotonin, and dopamine (DA), cause clinically significant depression in more than $15 \%$ of patients. Patients with major depression have symptoms that reflect changes in brain monoamine neurotransmitters, specifically NE, serotonin, and DA. According to a World Health Report, about 450 million people suffer from a mental or behavioral disorder, yet only a small proportion of them receive even the basic treatment [1]. Depression accounts for about $12 \%$ of the global burden of disease which is expected to rise to $15 \%$ by 2020 . The major problems of existing allopathic antidepressant drugs include delayed clinical benefit, serious side effects, and a response rate of $<50 \%$. Commonly used drugs for depression are monoamine oxidase (MAO) inhibitors and tricyclic antidepressants (TCAs). They increase the synaptic concentration of at least two of three neurotransmitters, namely, 5-hydroxytryptamine or serotonin (5-HT), NE, and DA. The combined effect of serotonin selective reuptake inhibitor (SSRI) and serotonin reuptake transporter inhibitor increases the synaptic concentration of 5-HT and its duration of action. Ethanolic extracts of most of the herbal drugs are rich in chemical constituents such as phenolic compounds, flavonoids, triterpenoids, and steroids. Ethanolic extracts have less harmful effects, availability, and lower cost of medicinal plants versus synthetic substances make them as outstanding and simple selection in the treatment of nervous diseases. Therefore, identification and validation of plant-derived substances for the treatment of various depressive disorders attract the attention of researchers [2].

Lagerstroemia speciosa L. is also known as the crepe myrtle or Pride of India or Banaba belongs to the family (Lythraceae). Lagerstroemia is named for the Swedish merchant, Magnus von Lagerstrom, was honored by Linnaeus, speciosa means showy, referring to the flowers varying in color from pink to purple. The tree is native to Southeast Asia and is called Banaba in the Philippines [3]. The flowers and leaves are used to make an herbal tea, as they contain corosolic acid, a chemical that has an insulin-like effect of lowering glucose levels in the body. It is also utilized in weight loss management [4].

\section{METHODS}

Collection and authentication of plant

The twigs (leaves, flowers, and fruits) of L. speciosa L. were collected from Mahapalika Garden, Bhayandar East, Thane. Sample specimen voucher was submitted to Dr. Rajendra D. Shinde, Director, Blatter Herbarium of St. Xavier's College, Mumbai. The leaves were compared and authenticated by comparison with the Blatter Herbarium Specimen No. JF-1532 of J. Fernandez. 
The leaves were washed with tap water and shade dried at normal room temperature with the aid of circulating airflow using a fan, and dried leaves were ground to make a coarse powder.

\section{Preparation of extract}

The powdered plant leaves of $L$. speciosa L. were extracted with ethanol in the Soxhlet apparatus. The content of the round bottom flask was emptied in the Petri plate, and the solvent was allowed to evaporate. The extract was evaporated to obtain the dry powder of extract. This crude dry extract was stored in a suitable container and kept in the refrigerator $(0-4)^{\circ} \mathrm{C}$ until use.

\section{Physicochemical analysis of powdered leaves}

Physicochemical parameters were carried out on powdered leaves of L. speciosa L. for loss on drying, total ash value, acid-insoluble ash value, water-soluble ash value, and determination of extractive values and were investigated as described by the well-established methods $[5,6]$.

\section{Preliminary phytochemical screening of the extract}

Preliminary chemical tests were carried out on the ethanolic extract of L. speciosa L. for the determination of the presence of phytoconstituents such as alkaloids, flavonoids, cardiac glycosides, saponins, steroids, terpenoids, tannins, and phenolic compounds and were investigated as described by the well-established methods $[5,6]$.

\section{Experimental animals}

Female albino wistar rats (200-300 g) were used for the study. The animals were obtained from SA-FORD, Plot No.: V-10, MIDC, Taloja, Navi Mumbai, Dist. Raigad Maharashtra - 410 208. The use of these animals and the study protocols were approved by CPCSEA recognized the Institutional Animal Ethical Committee (IAEC) of Oriental College of Pharmacy, Sanpada, Navi Mumbai - 400705 under protocol no. OCP/IAEC/2018-19/08. Rats were kept at the animal house in polypropylene cages (three in each cage), at $22 \pm 2^{\circ} \mathrm{C}$, with $12: 12 \mathrm{~h}$ dark: light cycle. They were provided with commercial rat feed and water given ad libitum. The animals were allowed to acclimatize for 7 days before the study.

\section{Selection of doses}

In the literature survey, it was found that the ethanolic extract of L. speciosa $\mathrm{L}$. was safe. $\mathrm{LD}_{50}$ of the ethanolic extract is reported to be $3000 \mathrm{mg} / \mathrm{kg}$ [7]. The plant is often eaten by animals, which is also an indicator to prove it is less toxic. Thus, for the purpose of the research study, the doses of ethanolic extract of Lagerstroemia speciosa (EELS) were finalized $100 \mathrm{mg} / \mathrm{kg}$ and $300 \mathrm{mg} / \mathrm{kg}$.

\section{Drugs and chemicals}

Imipramine hydrochloride (Abbott, Mumbai, India) was used as reference standards for the antidepressant activity.

\section{Experimental design}

Thirty female albino wistar rats were randomly divided into five experimental groups containing six rats each as shown in Table 1. Group-I (normal control) rats received normal saline $(2.0 \mathrm{ml} / \mathrm{kg}$, p.o.) daily for 14 days; Group-II (stress control) rats received normal saline $(2.0 \mathrm{ml} / \mathrm{kg}$, p.o.) daily for 14 days and subjected to restraint stress on the $13^{\text {th }}$ day. Group-III (standard drug-treated) rats received imipramine
(15 mg/kg, p.o.) daily for 14 days and subjected to restraint stress on the $13^{\text {th }}$ day. Groups-IV and V rats were treated with EELS $(100 \mathrm{mg} /$ $\mathrm{kg}$ and $300 \mathrm{mg} / \mathrm{kg}$, p.o.) daily for 14 days subjected to acute restraint stress (ARS) on the $13^{\text {th }}$ day.

Depression-like behavior was assessed by subjecting the rats to behavioral paradigms such as tail-suspension test (TST) and open field test (OFT), 40 min post-restraint stress procedure. Pretest of $10 \mathrm{~min}$ for forced swim test (FST) was also given to each rat simultaneously. Then, $23.5 \mathrm{~h}$ later, the relevant samples were administered and the main test performed 30 min later.

Oxidative stress parameters such as superoxide dismutase (SOD), catalase (CAT), malondialdehyde (MDA), and extent of lipid peroxidation (LPO) were analyzed in restraint stress-induced animals and control group, following FST on the $15^{\text {th }}$ day.

\section{Procedure for ARS}

ARS was accomplished by placing rats in an individual plastic rodent restraint device for $12 \mathrm{~h}$. This restrained all physical movements without subjecting the animal to pain. Animals were deprived of food and water during the entire period of exposure to stress. After $12 \mathrm{~h}$, the animals were released from their enclosure and $40 \mathrm{~min}$ post-release, the animals were subjected to behavioral tests and then to biochemical estimations. In the normal control group, the rats were kept in the animal cage in the experimental room $[8,9]$.

\section{Behavioral tests}

TST

The animals were suspended individually by the end of the tail with micropore adhesive tape (approximately $1 \mathrm{~cm}$ ) with the head $50 \mathrm{~cm}$ from the bottom in a suspension box $40 \mathrm{~min}$ post-restraint stress procedure. Rats were suspended for a total of $6 \mathrm{~min}$. During the final 4 min interval of the test, the duration of immobility was recorded. Rats were considered immobile only when they will be hung passively and absolutely motionless. Antidepressant decreases the immobility of the rat in this test [10].

OFT

Open-field apparatus was made as reported, each rat was placed in the center of the open field, and its behavior observed for $5 \mathrm{~min}$. The parameters evaluated were the total number of squares crossed, the number of outer squares (those adjacent to the walls) crossed, and the number of inner squares crossed; the three measures referred to as total (TL), peripheral (PL), and central locomotion, respectively. The numbers of leanings (one or two paws in contact with the wall), rearing (the mouse standing on its two hind paws without touching the walls), grooming (face cleaning, paw licking, fur licking, head scraping, and rubbing), and defecations were also recorded. At the end of each test, the whole area was cleaned with a wet sponge and a dry paper towel [11].

FST

On day 14, all the rats were allowed to swim individually for $10 \mathrm{~min}$ for adaptation. Then, $23.5 \mathrm{~h}$ later, the relevant samples were administered and the main test performed $30 \mathrm{~min}$ later, i.e., on day 15 . Rats were

Table 1: Grouping of animals

\begin{tabular}{|c|c|c|c|c|c|}
\hline S. No. & Groups & Test substances & Animal required per group (female albino wistar rats) & Dose & Total number \\
\hline 1. & Normal control & Normal saline & 6 & $2 \mathrm{ml} / \mathrm{kg}$ & 6 \\
\hline 2. & Stress control & Normal saline & 6 & $2 \mathrm{ml} / \mathrm{kg}$ & 6 \\
\hline 3. & Standard control & Imipramine & 6 & $15 \mathrm{mg} / \mathrm{kg}$ & 6 \\
\hline 4. & Test group 1 & EELS & 6 & $100 \mathrm{mg} / \mathrm{kg}$ & 6 \\
\hline 5. & Test group 2 & EELS & 6 & $300 \mathrm{mg} / \mathrm{kg}$ & 6 \\
\hline \multicolumn{5}{|c|}{ Total animals required } & 30 \\
\hline
\end{tabular}

EELS: Ethanolic extract of Lagerstroemia speciosa 
forced to swim in a cylinder (diameter $40 \mathrm{~cm}$, height $60 \mathrm{~cm}$ ) containing $30 \mathrm{~cm}$ of freshwater maintained at $25^{\circ} \mathrm{C} \pm 1^{\circ} \mathrm{C}$. Water in the cylinder was changed after each animal to prevent behavioral alteration among animals due to used water. Each animal showed vigorous movement during the initial 2 min period of the test. Duration of immobility will be manually recorded during the next 4 min of a total 6 min testing period by the observer. Rats were considered to be immobile when they floated in an upright position, making only small movements to keep their heads above the water level. Following the swimming session, rats were dried using a cotton towel and returned to home cages after the experiment. A decrease in the duration of immobility is indicative of antidepressant-like effect, whereas an increase of immobility time, when compared with the control group, is associated with depressivelike effects $[12,13]$.

\section{Biochemical estimation}

Preparation of brain tissue homogenate

All the animals were sacrificed by euthanasia using the $\mathrm{CO}_{2}$ chamber as per rodent euthanasia guidelines, after behavioral observations. The brains were quickly removed, washed in ice-cold sterile isotonic saline, and weighed. A $10 \%(\mathrm{w} / \mathrm{v})$ tissue homogenates were prepared with 0.1 Mphosphate buffer ( $\mathrm{pH} 7.4$ ). The supernatant was obtained by centrifugation of the homogenate at $1000 \mathrm{rpm}$ for $20 \mathrm{~min}$ at $5^{\circ} \mathrm{C}$ and used for further biochemical estimation [14].

\section{CAT activity}

The supernatant $(50 \mu \mathrm{l})$ was added to a cuvette containing $2.95 \mathrm{ml}$ of $19 \mathrm{mM} / \mathrm{L}$ solution of $\mathrm{H}_{2} \mathrm{O}_{2}$ prepared in potassium phosphate buffer. The change in absorbance was monitored at $240 \mathrm{~nm}$ wavelength at the 1 min interval for $3 \mathrm{~min}$. The presence of CAT decomposes $\mathrm{H}_{2} \mathrm{O}_{2}$ leading to a decrease in absorbance [15]

Sodium oxide dismutase activity

The SOD activity in the supernatant was measured by the method of Misra and Fridovich. The supernatant $(500 \mu \mathrm{l})$ was added to $0.800 \mathrm{ml}$ of carbonate buffer (100 mM, pH 10.2) and $100 \mu \mathrm{l}$ of epinephrine

Table 2: Result of physicochemical analysis of powdered leaves of Lagerstroemia speciosa

\begin{tabular}{lll}
\hline Sr. No. & Test & Result (\%) \\
\hline 1. & Loss on drying & 60.67 \\
2. & Total ash value & 16.39 \\
3. & Acid-insoluble ash value & 6.24 \\
4. & Water-soluble ash value & 7.58 \\
5. & Petroleum ether soluble extractive value & 9.6 \\
6. & Chloroform soluble extractive value & 6.4 \\
7. & Ethyl acetate soluble extractive value & 2.4 \\
8. & Ethanol soluble extractive value & 8.8 \\
9. & Water-soluble extractive value & 15.2 \\
\hline
\end{tabular}

( $3 \mathrm{mM}$ ). The change in absorbance of each sample was then recorded at $480 \mathrm{~nm}$ in spectrophotometer for $2 \mathrm{~min}$ at an interval of $15 \mathrm{~s}$. Parallel blank and standard were run for determination of SOD activity. The reaction mixtures are diluted $1 / 10$ just before taking the readings in a spectrophotometer [16].

\section{Determination of MDA formation}

To $1 \mathrm{ml}$ of suspension medium was taken from the $10 \%$ tissue homogenate. To $0.5 \mathrm{ml}$ of $30 \%$ TCA will be added to it, followed by $0.5 \mathrm{ml}$ of $0.8 \%$ thiobarbituric acid (TBA) reagent. The tubes were then be covered with aluminum foil and kept in shaking water bath for $30 \mathrm{~min}$ at $80^{\circ} \mathrm{C}$. After $30 \mathrm{~min}$, tubes were taken out and kept in ice-cold water for $30 \mathrm{~min}$. These were then be centrifuged at $3000 \mathrm{rpm}$ for $15 \mathrm{~min}$.

The absorbance of the supernatant was read at $540 \mathrm{~nm}$ at room temperature against an appropriate blank. Blank consists of $1 \mathrm{ml}$ distilled water, $0.5 \mathrm{ml}$ of $30 \%$ TCA and $0.5 \mathrm{ml}$ of $0.8 \%$ TBA [17].

\section{Determination of LPO assay}

To $0.2 \mathrm{ml}$ of the test sample, $0.2 \mathrm{ml}$ of SDS, $1.5 \mathrm{ml}$ of acetic acid, and $1.5 \mathrm{ml}$ of TBA were added. The mixture was made up to $4 \mathrm{ml}$ with water and then heated in a water bath at $95^{\circ} \mathrm{C}$ for $60 \mathrm{~min}$. After cooling, $1 \mathrm{ml}$ of water and $5 \mathrm{ml}$ of n-butanol/pyridine mixture were added and agitated smartly. After centrifugation at $4000 \mathrm{rpm}$ for $10 \mathrm{~min}$, the organic layer was taken and its absorbance was scan at $532 \mathrm{~nm}$. The level of lipid peroxides was expressed as nmoles of MDA released/g wet tissue [17]

\section{Statistical analysis}

The data obtained from animal experiments were analyzed with InStat Software by GraphPad (version 3.10). It was expressed as mean \pm standard error of the mean. For statistical analysis, the data were subjected to analysis of variance followed by Dunnett's t-test. Results were considered to be statistically significant at $p \leq 0.05$. Significance levels were as follows:

*Indicates $\mathrm{p} \leq 0.05$ as significant; **indicates $\mathrm{p} \leq 0.01$ as highly significant; $* * *$ indicated $\mathrm{p} \leq 0.001$ as very significant.

\section{RESULTS}

Physicochemical analysis of powdered leaves

The result of Physicochemical analysis of powdered leaves of Lagerstroemia speciosa are shown in Table 2.

\section{Qualitative phytochemical screening}

The result of quantitative phytochemical analysis of powdered leaves of Lagerstroemia speciosa are shown in Table 3.

\section{Antidepression evaluation}

TST

Both the doses of the ethanolic extract of leaves of L. speciosa L. showed a dose-dependent decrease in immobility time when compared against

Table 3: Result of quantitative phytochemical analysis of powdered leaves of Lagerstroemia speciosa

\begin{tabular}{llll}
\hline S. No. & Phytoconstituents & Test & Ethanolic extract of the leaves Lagerstroemia speciosa L. \\
\hline 1. & Carbohydrates & Molisch's test & $+\mathrm{ve}$ \\
& & Fehling's test & $+\mathrm{ve}$ \\
2. & Proteins and free amino acids & Ninhydrin test & $-\mathrm{ve}$ \\
3. & Alkaloids & Mayer's test & $-\mathrm{ve}$ \\
4. & Cardiac glycosides & Keller-Kiliani test & $+\mathrm{ve}$ \\
5. & Steroids & Liebermann-Burchard test & $+\mathrm{ve}$ \\
6. & Terpenoids & Salkowski test & $+\mathrm{ve}$ \\
7. & Tannins & $5 \% \mathrm{FeCl}_{3}$ solution & $+\mathrm{ve}$ \\
8. & Flavonoids & Shinoda test & $+\mathrm{ve}$ \\
9. & Phenols & Lead acetate test & $+\mathrm{ve}$ \\
10. & Saponins & Foam test & $-\mathrm{ve}$ \\
\hline
\end{tabular}

+ve: Present, -ve: Absent 
stress control as well as against imipramine which was used as a standard. The results of TST are shown in Table 4 and Fig. 1.

\section{OFT}

Both the doses of the ethanolic extract of leaves of L. speciosa L. showed a dose-dependent increase in locomotor activity when compared against stress control as well as against imipramine which was used as a standard. The results of TST are shown in Table 5 and Fig. 2.

FST

Both the doses of the ethanolic extract of leaves of $L$. speciosa L. showed a dose-dependent decrease in immobility time when compared against stress control as well as against imipramine which was used as a standard. The results of TST are shown in Table 6 and Fig. 3 .

\section{Biochemical estimations}

CAT activity

Evaluation of CAT activity revealed that stressed rats presented a significant decrease in CAT activity, which was significantly prevented by EELS ( $100 \mathrm{mg} / \mathrm{kg}$ and $300 \mathrm{mg} / \mathrm{kg}$ ) pre-treatment when compared to unstressed group, as shown in Table 7 and Fig. 4.

\section{SOD activity}

In the rats pretreated with EELS $100 \mathrm{mg} / \mathrm{kg}$ and $300 \mathrm{mg} / \mathrm{kg}$ p.o., the level of SOD was significantly increased $(\mathrm{p}<0.001)$ as compared to ARS rats. Table 7 and Fig. 5 show significant and dose-dependent recovery on ARS induced reduced level of SOD in the animal due to EELS.

\section{MDA formation}

The results depicted in Table 7 and Fig. 6 illustrate that ARS significantly increased MDA level in rat brain as compared to unstressed rats. The results indicated that EELS $(100 \mathrm{mg} / \mathrm{kg}$ and $300 \mathrm{mg} / \mathrm{kg})$ pre-treatment and imipramine significantly abolished the increase in MDA level caused by ARS.

\section{LPO assay}

Quantitative measurement of LPO in the whole brain was assessed based on the amount of MDA formed, the statistical analysis revealed that ARS produced a significant increase in MDA level whereas EELS $(100 \mathrm{mg} / \mathrm{kg}$ and $300 \mathrm{mg} / \mathrm{kg}$ ) pre-treatment significantly abolished the increase in MDA level compared to stressed animals. The results are shown in Table 7 and Fig. 7.

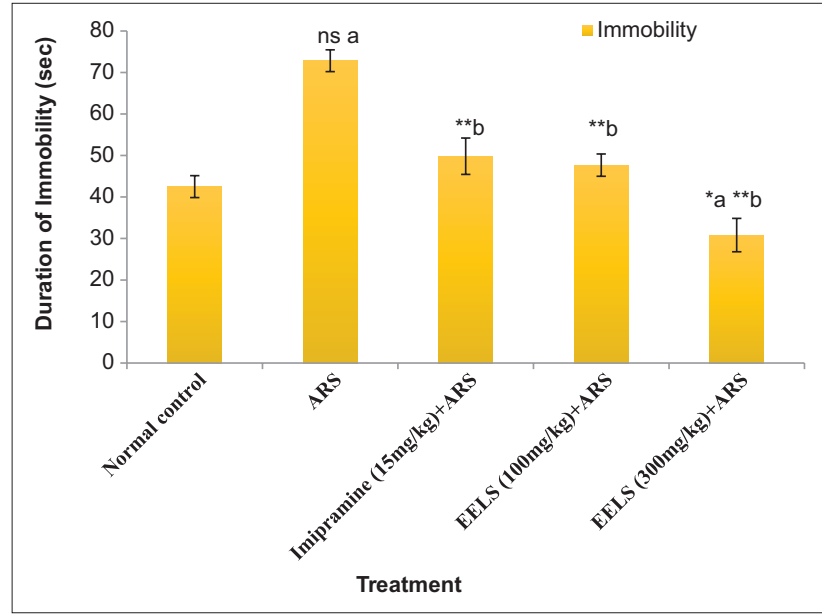

Fig. 1: Effect of the ethanolic extract of Lagerstroemia speciosa L. leaves on immobility time of tail suspension test in albino wistar rats. a Versus normal control group and b versus acute restraint stress group

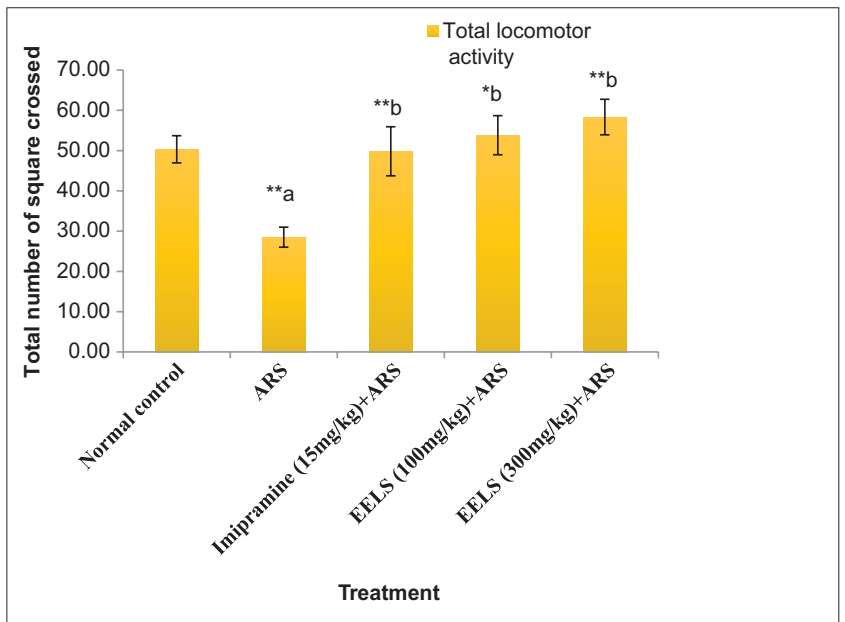

Fig. 2: Effect of the ethanolic extract of Lagerstroemia speciosa $\mathrm{L}$. leaves on locomotor activity of open field test in albino wistar rats. a Versus normal control group and $b$ versus acute restraint stress group

Table 4: Effect of ethanolic extract of Lagerstroemia speciosa L. leaves on immobility time of tail suspension test in albino wistar rats

\begin{tabular}{lll}
\hline S. No. & Treatment & Duration of immobility (s) \\
\hline 1. & Normal control & $112.17 \pm 12.60$ \\
2. & ARS & $145.17 \pm 12.46$ \\
3. & Imipramine (15 mg/kg p.o.)+ARS & $79.16 \pm 4.67^{* *}$ \\
4. & EELS (100 mg/kg p.o.)+ARS & $82.83 \pm 6.90^{* *}$ \\
5. & EELS (300 mg/kg p.o.)+ARS & $70.16 \pm 5.18^{* *}$ \\
\hline
\end{tabular}

Values are the mean \pm standard error of the mean of $\mathrm{n}=6$ rats/treatment. Significance ${ }^{* *} \mathrm{p} \leq 0.01$. ARS: Acute restraint stress, EELS: Ethanolic extract of Lagerstroemia speciosa

Table 5: Effect of the ethanolic extract of Lagerstroemia speciosa L. leaves on locomotor activity of open field test in albino wistar rats

\begin{tabular}{|c|c|c|c|c|c|c|c|c|}
\hline S. No. & Treatment & Total & Peripheral & Central & Leaning & Rearing & Grooming & Defecation \\
\hline 1. & Normal control & $50.33 \pm 3.38$ & $46.00 \pm 3.51$ & $4.33 \pm 1.49$ & $9.00 \pm 2.59$ & $0.83 \pm 0.4$ & $3.17 \pm 0.60$ & $2.83 \pm 1.4$ \\
\hline 2. & ARS & $28.50 \pm 2.49 * *$ & $26.17 \pm 2.53$ & $2.17 \pm 0.17$ & $11.5 \pm 3.4$ & $1.5 \pm 1.15$ & $3.00 \pm 0.68$ & $0.83 \pm 0.65$ \\
\hline 3. & Imipramine $(15 \mathrm{mg} / \mathrm{kg})+\mathrm{ARS}$ & $49.83 \pm 6.09 * *$ & $43.67 \pm 6.70$ & $6.50 \pm 2.90$ & $10.17 \pm 2.21$ & $3.17 \pm 2.21$ & $4.67 \pm 1.09$ & $0.67 \pm 0.33$ \\
\hline 4. & $\operatorname{EELS}(100 \mathrm{mg} / \mathrm{kg})+\mathrm{ARS}$ & $53.83 \pm 4.85^{*}$ & $48.50 \pm 5.31$ & $2.33 \pm 0.76$ & $8.00 \pm 2.48$ & $2.83 \pm 0.31$ & $3.50 \pm 0.76$ & $3.00 \pm 1.03$ \\
\hline 5. & EELS $(300 \mathrm{mg} / \mathrm{kg})+A R S$ & $58.33 \pm 4.40^{* *}$ & $52.50 \pm 4.56$ & $3.00 \pm 1.03$ & $5.17 \pm 1.76$ & $1.17 \pm 0.54$ & $1.50 \pm 0.50$ & $2.17 \pm 0.98$ \\
\hline
\end{tabular}

Values are the mean \pm standard error of the mean of $\mathrm{n}=6$ rats/treatment. Significance ${ }^{* *} \mathrm{p} \leq 0.01,{ }^{*} \mathrm{p} \leq 0.05$. EELS: Ethanolic extract of Lagerstroemia speciosa, ARS: Acute restraint stress 


\section{DISCUSSION}

The incidence of depression in the community is very high and is associated with a lot of diseases. Hence, it is very important to report these problems and find effective remedies. Several drugs are available, all are associated with some limitations and there is a crucial need for alternative medications for these disorders. Medical therapies with herbs may be effective alternatives in the treatment of depression, and the research of their effects has progressed significantly since the past decade $[18,19]$.

Table 6: Effect of the ethanolic extract of Lagerstroemia speciosa $\mathrm{L}$. leaves on immobility time of force swim test in albino wistar rats

\begin{tabular}{lll}
\hline S. No. & Treatment & $\begin{array}{l}\text { Duration of } \\
\text { immobility (s) }\end{array}$ \\
\hline 1. & Normal control & $42.50 \pm 2.63$ \\
2. & ARS & $72.83 \pm 2.63^{* *}$ \\
3. & Imipramine (15 mg/kg p.o.) +ARS & $49.83 \pm 4.38^{* *}$ \\
4. & EELS (100 mg/kg p.o.)+ARS & $49.67 \pm 2.70^{* *}$ \\
5. & EELS (300 mg/kg p.o.)+ARS & $30.83 \pm 4.03^{* *}$ \\
\hline
\end{tabular}

Values are the mean \pm standard error of the mean of $n=6$ rats/treatment. Significance ${ }^{* *} \mathrm{p} \leq 0.01$. EELS: Ethanolic extract of Lagerstroemia speciosa, ARS: Acute restraint stress

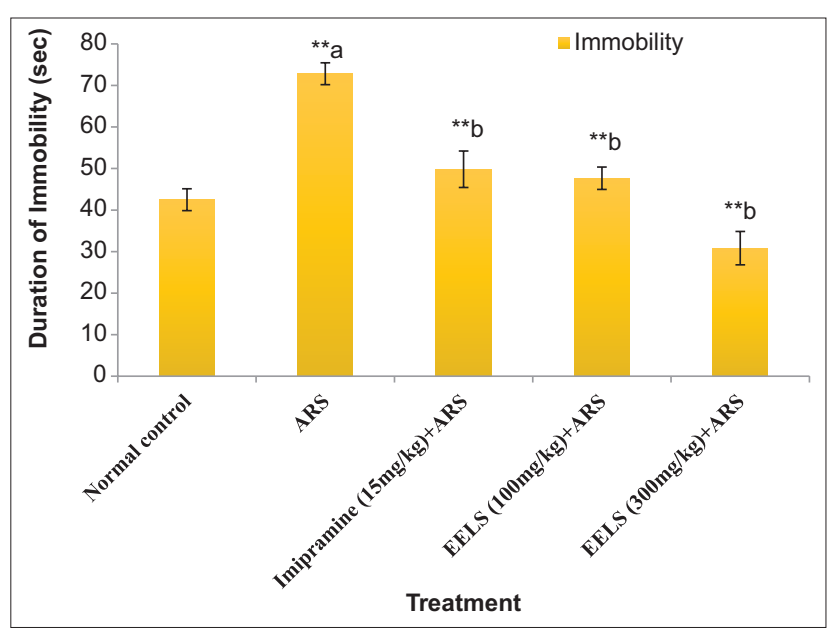

Fig. 3: Effect of the ethanolic extract of Lagerstroemia speciosa L. leaves on immobility time of force swim test in albino wistar rats. a Versus normal control group and b versus acute restraint stress group

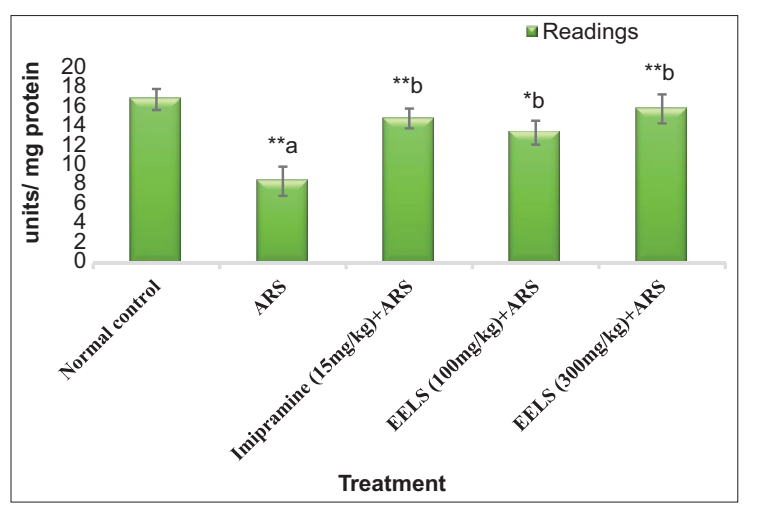

Fig. 4: Effect of EELS pre-treatment on ARS induced changes on catalase activity. NC: Normal control, ARS: Acute restraint stress,

EELS: Ethanolic extract of Lagerstroemia speciosa. Values are expressed as mean \pm standard error of the mean $(n=6) . * * p \leq 0.01$ and ${ }^{*} p \leq 0.05$, a versus NC group and $b$ versus ARS group
The introduction of drugs such as amitriptyline, fluvoxamine, imipramine, citalopram, venlafaxine, and others has modernized the treatment of depression. The marvellous efficacy of imipramine in these depressive disorders has paved the way for the introduction and use of newer antidepressant agents. However, the safety factor in respect of the imipramine antidepressant drugs has been rather intriguing and hence a definite need is visualized for the introduction of safer antidepressant drugs having no troublesome adverse effects [20].

The ARS was used as a model of depression induced by stress, which has both emotional and physical components in combination to distress the brain's intracellular redox status. The main purpose of using restraint is that it induces an inescapable physical and mental stress which is not accompanied by a conditioned response. It is important to clarify that this study was performed in female rats because women are more susceptible to the development of depressive disorder followed to lifetime stress events than men [21].

The behavior despair test (TST and FST) is quite sensitive and relatively specific to all major classes of antidepressant drugs, including tricyclics, SSRI, MAO inhibitors, and atypicals. Imipramine is a presynaptic uptake inhibitor of both nor-adrenaline and serotonin. Since catecholamines and 5-HT have been implicated in the etiology of

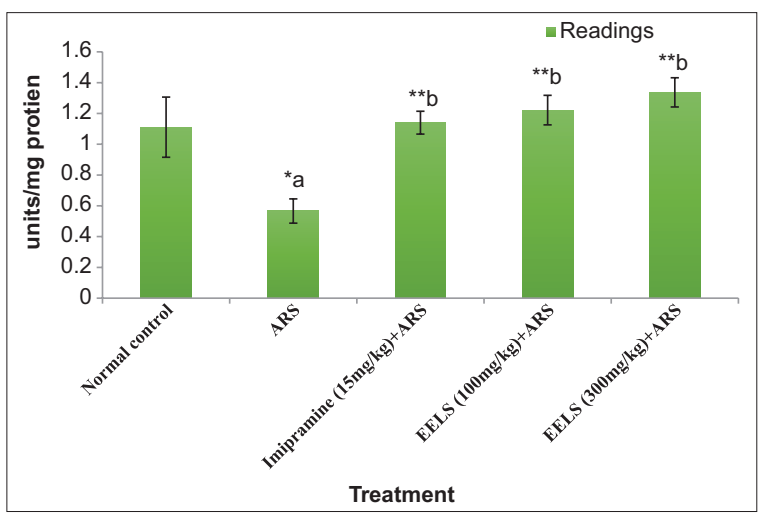

Fig. 5: Effect of EELS pre-treatment on ARS induced changes on SOD activity. NC: Normal control, ARS: Acute restraint stress, EELS: Ethanolic extract of Lagerstroemia speciosa. Values are expressed as mean \pm standard error of the mean $(n=6) . * * p \leq 0.01$ and $* \mathbf{p} \leq 0.05$, a versus NC group and $b$ versus ARS group

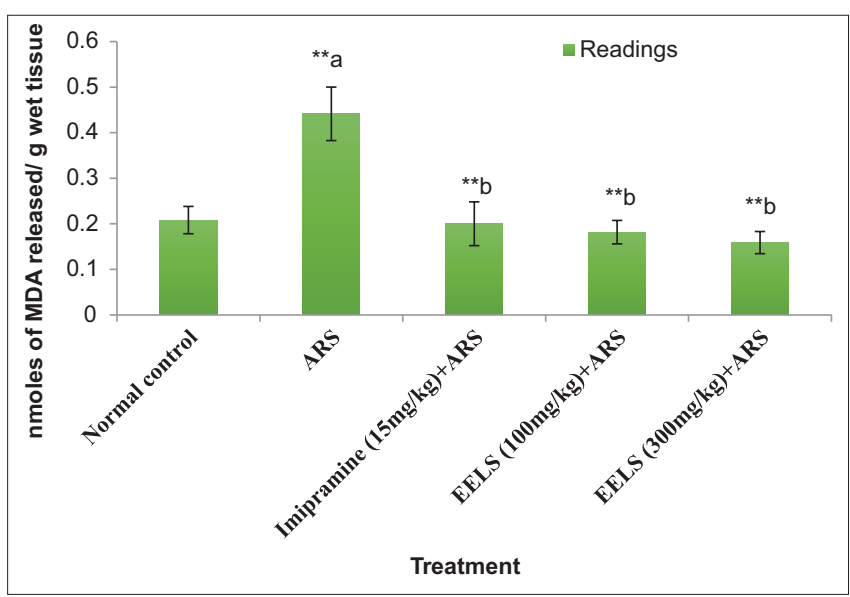

Fig. 6: Effect of EELS pre-treatment on ARS induced changes on MDA activity. NC: Normal control, ARS: Acute restraint stress, EELS: Ethanolic extract of Lagerstroemia speciosa. Values are expressed as mean \pm standard error of the mean $(n=6) .{ }^{* *} p \leq 0.01$, a versus NC group and $b$ versus ARS group 
Table 7: Effect of oxidative stress markers in brain

\begin{tabular}{|c|c|c|c|c|c|}
\hline S. No. & Treatment & Catalase & Superoxide dismutase & Malondialdehyde & Lipid peroxidation \\
\hline 1. & Normal control & $16.81 \pm 1.082$ & $1.12 \pm 1.082$ & $0.21 \pm 0.030$ & $0.107 \pm 0.004$ \\
\hline 2. & ARS & $8.41 \pm 1.502$ & $0.57 \pm 0.079$ & $0.45 \pm 0.059$ & $0.355 \pm 0.050$ \\
\hline 3. & Imipramine $(15 \mathrm{mg} / \mathrm{kg})+\mathrm{ARS}$ & $14.86 \pm 1.019 * *$ & $1.15 \pm 0.075^{* *}$ & $0.20 \pm 0.048^{* *}$ & $0.142 \pm 0.015^{* *}$ \\
\hline 4. & EELS $(100 \mathrm{mg} / \mathrm{kg})+\mathrm{ARS}$ & $13.4 \pm 1.226^{* *}$ & $1.23 \pm 0.093^{* *}$ & $0.18 \pm 0.026^{* *}$ & $0.133 \pm 0.010^{* *}$ \\
\hline 5. & EELS (300 mg/kg)+ARS & $15.85 \pm 1.485^{* *}$ & $1.34 \pm 0.095^{* *}$ & $0.16 \pm 0.025^{* *}$ & $0.123 \pm 0.012^{* *}$ \\
\hline
\end{tabular}

Values are the mean \pm standard error of the mean of $n=6$ rats/treatment. Significance ${ }^{* *} \mathrm{p} \leq 0.01$. a versus NC group and $b$ versus ARS group. EELS: Ethanolic extract of Lagerstroemia speciosa, ARS: Acute restraint stress

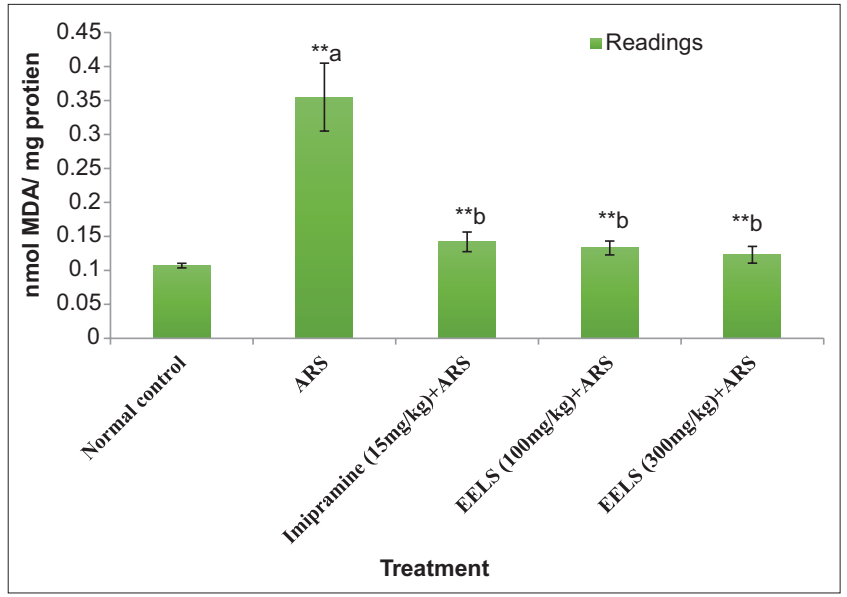

Fig. 7: Effect of EELS pre-treatment on ARS induced changes on LPO activity. NC: Normal control, ARS: Acute restraint stress, EELS: Ethanolic extract of Lagerstroemia speciosa. Values are expressed as mean \pm standard error of the mean $(n=6)$. ${ }^{* *} p \leq 0.01$, a versus NC group and $b$ versus $A R S$ group

depression, the positive effect of these drugs in TST and FST seems to be due to increased availability of these neurotransmitters at the post-synaptic receptor sites following their reuptake inhibition. In the current study, ARS significantly increased the immobility time in the FST and TST indicating depressive-like behavior which showed that restraint stress-induced depressive-like behavior as evidenced by increased immobility time in FST and TST. This immobility reflects a state of despair in animals and is claimed to reproduce a condition similar to depression in humans. Animals after antidepressant treatment feel amazing even in desperate situations, and they spend less time with immobility. In the present study, EELS in the dose of 100 and $300 \mathrm{mg} / \mathrm{kg}$ showed a significant dose-dependent antidepressantlike effect in behavior despair test (TST and FST), as they reduced the immobility time when compared against stress control as well as against standard imipramine $(15 \mathrm{mg} / \mathrm{kg})$ showing that in both the doses, it has significant antidepressant activity.

Similarly, restraint stress caused a significant decrease in central and PL crossings in the OFT, indicating depression-like behavior. The dose of $100 \mathrm{mg} / \mathrm{kg}$ and $300 \mathrm{mg} / \mathrm{kg}$ of EELS increased the number of central and PL crossings. The observed results showed a significant dose-dependent antidepressant-like effect in OFT, as they increase in locomotor activity when compared against stress control as well as against standard imipramine $(15 \mathrm{mg} / \mathrm{kg})$ showing that in both the doses, it has significant antidepressant activity.

The exact mechanism by which extract of EELS leaves exert antidepressant action is not precisely known. The leaves of EELS contain phenolic compounds and many flavonoids such as quercetin, isoquercetin, and kaempferol. Phenolic compounds and flavonoids have been reported to inhibit catechol-0-methyltransferase and MAO enzymes in the brain. Hence, it increases the concentration of catecholamines in synaptosomes and thus attenuates depression. Oxidative stress is one of the mechanisms involved in the pathogenesis of depression. Many natural products have an antioxidant property which is involved in reversing the deleterious effects of neuronal communication and behavior. CAT and SOD are one of the free radicals suggested, role in stress and depression either by modulating the release of other neurotransmitters, decrease in SOD activity, and decrease in CAT activity induced as a result of ARS, is an index of pro-oxidative conditions. In the present study, $12 \mathrm{~h}$ restraint stress-induced significant oxidative damage, as indicated by decreased SOD and decreased CAT, which was significantly normalized by EELS pre-treatment in a dose-dependent manner [22].

MDA and LPO are considered as a critical mechanism in causing cell injury during oxidative stress. Several studies have shown that restraint stress significantly elevated the concentration of MDA levels in the hippocampus of rats. The present study results show a significant concentration of MDA level, evidenced by an increased amount of MDA, which was significantly normalized by EELS pre-treatment in a dose-dependent manner. Thus, the antidepressant-like effect of EELS could be associated with its capacity to prevent the MDA and lipid peroxidative damage, induced by ARS [23].

\section{CONCLUSION}

It can be concluded from the study that the ethanolic extract of $L$. speciosa L. leaves possesses significant antidepressant property, which is probably due to flavonoids which play an active role in providing antidepressant-like effect. L. speciosa L. plant can be used for the treatment of neurological disorders and may be recommended as a supplement for the antidepressant activity.

\section{ACKNOWLEDGMENT}

We are grateful to SA-FORD, Plot No.: V-10, MIDC, Taloja, Navi Mumbai, Dist. Raigad Maharashtra - 410208 for the donation of albino Wistar rats for the research. We are grateful to our Principal Dr. (Mrs.) Sudha Rathod and Prof. Imtiyaz Ansari for their guidance and support as well as to the Pharmacology Department, Oriental College of Pharmacy, Navi Mumbai.

\section{AUTHORS' FUNDING}

The authors received no specific funding for this research project work.

\section{AUTHORS' CONTRIBUTION}

We declare that this work was done by the authors named in this article and all liabilities pertaining to claims relating to the content of this article will be done by the authors. Miss Sunita Vishwakarma performed the research work collected the data and analyzed the data. Dr. (Mrs.) Vanita Kanase proof-read the whole manuscript and suggested the necessary changes and helps in designing the manuscript.

\section{CONFLICTS OF INTEREST}

The authors declare that there are no conflicts of interest regarding the publication of this paper. 


\section{REFERENCES}

1. Santosh P, Venugopl R, Nilakasha S, Kunjbihari S, Mangala L. Antidepressant activity of methanolic extract of Passiflora foetida leaves in mice. Int J Pharm Pharm Sci 2011;3:6-9.

2. Bharathi P, Seshayamma V, Jagannadharao GH, Sivakumar N. Evaluation of antidepressant activity of aqueous extract of Withania Somnifera [Aswagandha] roots in albino mice. IOSR J Pharm Biol Sci 2015;10:27-9.

3. Knox GW, Norcini JG. Lagerstroemia cultivars under evaluation at the NFREC-monticello. Proc Fla State Hortic Soc 1991;104:346-7.

4. Turner S. Queen's Crape Myrtle (Lagerstroemia speciosa) and Crape Myrtle (Lagerstroemia indica). Miami, FL: Richard Lyons Nursery, Inc.; 2016.

5. Kokate CK. Practical Pharmacognosy. $4^{\text {th }}$ ed. New Delhi, India: Vallabh Prakashan; 2005.

6. Khandelwal KR. Practical Pharmacognosy. Pune, Maharashtra: Nirali Prakashan; 2000

7. Azad AK, Rahman MK, Sunzida NK. Acute oral toxicity study on Malaysian traditional herb: Lagerstroemia speciosa L. (Banaba). J Pharmacogn Phytochem 2015;4:228-32.

8. Mostofsky DI, Buynitsky T. Restraint stress in biobehavioral research: Recent developments. Neurosci Biobehav Rev 2009;33:1089-98.

9. Takada T, Yoshinari N, Sugiishi S, Kawase H, Yamane T, Noguchi T. Effect of restraint stress on the progression of experimental periodontitis in rats. J Periodontol 2004;75:306-15.

10. Lotankar AR, Wankhede S, Sharma JB, Momin AJ. Anti-stress activity of flavonoids rutin and quercetin isolated from the leaves of Ficus benghalensis. Int J Pharm Pharm Res 2016;5:5-19.

11. Seyed AM, Hossein H, Fatemeh G. Evaluation of antidepressant effects of aerial parts of Echium vulgare on mice. Iran J Basic Med Sci 2007;10:189-96.

12. Sulakhiya K, Patel VK, Saxena R, Dashore J, Srivastava AK, Rathore M. Effect of Beta vulgaris Linn. Leaves extract on anxiety and depressivelike behavior and oxidative stress in mice after acute restraint stress. Pharmacognosy Res 2016;8:1-7.
13. Devi1 T, Das S. Evaluation of the protective effect of ethanolic extract of leaves of Punica granatum Linn. On forced swimming induced chronic fatigue syndrome in mice. Int J Pharm Pharm Sci 2017;9:207-12.

14. Thakarea VN, Dhakaneb VD, Patel BM. Potential antidepressant-like activity of silymarin in the acute restraint stress in mice: Modulation of corticosterone and oxidative stress response in cerebral cortex and hippocampus. Pharmacol Rep 2016;68:1020-7.

15. Aebi H. In: Bergmeyer HU, editor. Methods of Enzymatic Analysis. New York: Academic Press; 1974. p. 674.

16. Mishra HP, Fridovich I. The oxidation of phenylhydrazine: Superoxide and Mechanism. Biochemistry 1976;15:681-3.

17. Ohkawa H, Ohisi N, Yagi K. Assay for lipid peroxides in animal tissues by thiobarbituric acid reaction. Anal Biochem 1979;95:351-8.

18. Hasrat JA, De Bruyne T, De Backer JP, Vauquelin G, Vlietinck AJ. Isoquinoline derivatives isolated from the fruit of Annona muricata as 5-HTergic 5-HT1A receptor agonists in rats: Unexploited antidepressive (lead) products. J Pharm Pharmacol 1997;49:1145-9.

19. Hasrat JA, Pieters L, De Backer JP, Vauquelin G, Vlietinck AJ. Screening of medicinal plants from Suriname for 5-HT(1A) ligands: Bioactive isoquinoline alkaloids from the fruit of Annona muricata. Phytomedicine 1997;4:133-40.

20. Porsolt RD, Anton G, Blavet N, Jalfre M. Behavioural Despair in Rats: A new model sensitive to antidepressant treatments. Eur J Pharmacol 1978;47:379-91.

21. Freitas AE, Bettio L, Neis VB, Santos DB, Ribeiro CM, Rosa PB, et al. Agmatine abolishes restraint stress-induced depressive-like behavior and hippocampal antioxidant imbalance in mice. Prog Neuropsychopharmacol Biol Psychiatry 2014;50:143-50.

22. Budni J, Zomkowski AD, Engel D, Santos DB, dos Santos AA, Moretti M, et al. Folic acid prevents depressive-like behavior and hippocampal antioxidant imbalance induced by restraint stress in mice. Exp Neurol 2013;240:112-21.

23. Kolla N, Wei Z, Richardson JS, Li XM. Amitriptyline and fluoxetine protect PC12 cells from cell death induced by hydrogen peroxide. J Psychiatry Neurosci 2005;30:196-201. 